\title{
Erratum to: Update on Management of Cancer-Related Cachexia
}

\author{
Lindsey J. Anderson ${ }^{1}$ • Eliette D. Albrecht ${ }^{1,2}$ • Jose M. Garcia ${ }^{1,3}$
}

Published online: 14 March 2017

(C) Springer Science+Business Media New York 2017

\section{Erratum to: Curr Oncol Rep (2017) 19:3 \\ DOI 10.1007/s11912-017-0562-0}

The original version of this article, published in Current Oncology Reports, Volume 19, Issue 1, January 2017, contained misinterpreted data within the paragraph entitled "Nutritional Supplementation" on page 2 of the article. The authors offer their sincerest apologies regarding the incorrect statements in reference to Kapoor et al. 2016 [1]. It was pointed out that the definition of cachexia was not provided; however, the definition should be "weight loss of more than 5\% from pretreatment weight, body mass index less than $20 \mathrm{~kg} / \mathrm{m}^{2}$ along with hemoglobin level less than $12 \mathrm{~g} / \mathrm{dL}$, and energy intake of less than $1500 \mathrm{kcal} / \mathrm{d}$ were considered eligible for participation" [1]. It was also noted that the experimental supplementation consisted of a wheat flour mix when wheat was

The online version of the original article can be found at http://dx.doi. org/10.1007/s11912-017-0562-0

Jose M. Garcia

jg77@uw.edu

Lindsey J. Anderson

lindsey.anderson5@va.gov

Eliette D. Albrecht

eliette.albrecht@yale.edu

1 Geriatric Research, Education and Clinical Center (GRECC), VA Puget Sound Health Care System, Seattle, WA 98108, USA

2 Yale University, New Haven, CT 06520, USA

3 Department of Medicine, Division of Gerontology and Geriatric Medicine, University of Washington School of Medicine, Seattle, WA, USA not included as an ingredient. Finally, it was suggested that the baseline differences in energy intake "may have contributed to" the resultant changes in body composition; however, baseline data was adjusted for in the Kapoor et al. 2016 analyses which revealed increased energy intake in the experimental group. The amended paragraph provided is now correct.

Kapoor, N., et al., A Prospective Randomized Controlled Trial to Study the Impact of a Nutrition-Sensitive Intervention on Adult Women With Cancer Cachexia Undergoing Palliative Care in India. Integr Cancer Ther, 2016.

\section{Nutritional Supplementation}

A multisite, double-blinded RCT assessed 12 weeks of Lcarnitine $(4 \mathrm{~g} / \mathrm{d})$ or placebo in Stage IV pancreatic cancer patients with cachexia ( $>10 \%$ weight loss in the prior six months) [30]. L-carnitine improved gastrointestinal (GI) symptoms, QOL, BW, and percent body fat (PBF) and decreased malnutrition compared to placebo. Kapoor et al. assessed a nutrition counseling plus supplement intervention in Indian women with cancer cachexia ( $>5 \%$ weight loss from pre-treatment, BMI $<20 \mathrm{~kg} / \mathrm{m} 2$, hemoglobin $<12 \mathrm{~g} / \mathrm{dL}$, and energy intake $<1500 \mathrm{kcal} / \mathrm{d}$ ) [31]. Patients consumed $100 \mathrm{~g} /$ $\mathrm{d}$ of the nutrient-rich flour mix called Improved Atta (IAtta) in addition to their daily food intake for six months; the control group received counseling only. IAtta attenuated loss of BW and improved PBF, fatigue, appetite, and energy intake compared to control. The generalizability of these results is likely limited to those with this specific regional diet; however, other studies have failed to improve QOL or physical function [32]. 